\title{
AC 2009-1112: UNDERSTANDING AUTOMATED SYSTEM DESIGN PROBLEM SOLVING: CURRENT PROGRESS AND IMPLICATIONS FOR INSTRUCTION
}

\section{Sheng-Jen Hsieh, Texas A\&M University}

Dr. Sheng-Jen ("Tony") Hsieh is an Associate Professor in the Dwight Look College of Engineering at Texas A\&M University. He holds a joint appointment with the Department of Engineering Technology and the Department of Mechanical Engineering. His research interests include engineering education, cognitive task analysis, automation, robotics and control, intelligent manufacturing system design, and micro/nano manufacturing. He is also the Director of the Rockwell Automation laboratory at Texas A\&M University, a state-of-the-art facility for education and research in the areas of automation, control, and automated system integration. 


\section{Understanding Automated System Design Problem-Solving: Current Progress and Implications for Instruction}

Designing and building automated manufacturing systems-also known as system integrationis a complex cognitive task. It requires knowledge about the various mechanical and electrical devices available to make up the system-including their functions, power requirements, and specific characteristics - as well as the ability to write PLC programs to orchestrate and synchronize the process being automated. Development of expertise in system integration typically requires several years of industry experience. Needed is a deeper understanding of how engineers become experts in this area. This understanding can then be used to help students and new engineers to develop system integration skills reliably and efficiently.

For the past five years, the author has conducted interviews with engineers from 17 U.S. and 5 European system integration companies. The interviews were conducted in two rounds. The goal of the first round was to develop a basic understanding of the work environment within system integration firms, including types of projects, roles, constraints, and available tools and resources. These findings are reported in Hsieh $(2005)^{1}$.

One key finding was that system integration engineers generally work in teams and can be classified into one of three job types: application engineer, control engineer, and mechanical engineer. Application engineers tend to be the most experienced. Their job is to come up with a conceptual design for an automated system based on a customer's requirements. It is typically their responsibility to develop proposals and to communicate design information to customers and other members of their team.

In the second round of interviews, we continued to ask experts about their jobs and the system integration industry, with a particular focus on application engineers with 15 or more years of system integration experience. In addition, we added an exercise in which the application engineers were asked to come up with a design for an automated assembly line while thinking aloud. For example, in one exercise, the task was to design an automated cell phone assembly line given a set of seven parts, a \$1M budget, a six-second cycle time, and nine months to complete the project (Figure 1). In total, we have interviewed 48 engineers from 17 U.S. and 5 European system integration companies, and collected data from 18 think-aloud exercises (15 related to the cell phone assembly task and 3 related to a truck frame assembly task).
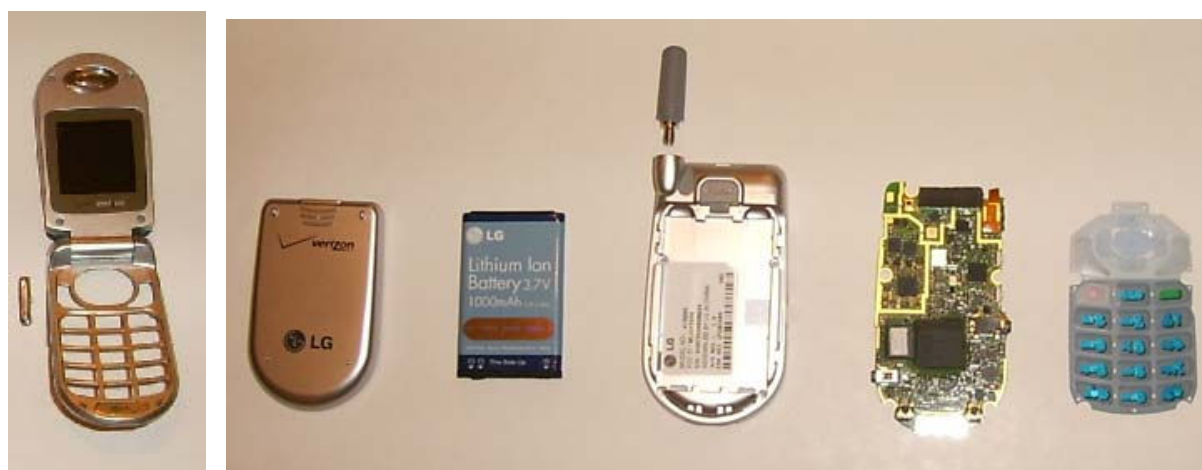

Figure 1. Cell phone parts used in conceptual design think-aloud exercise 


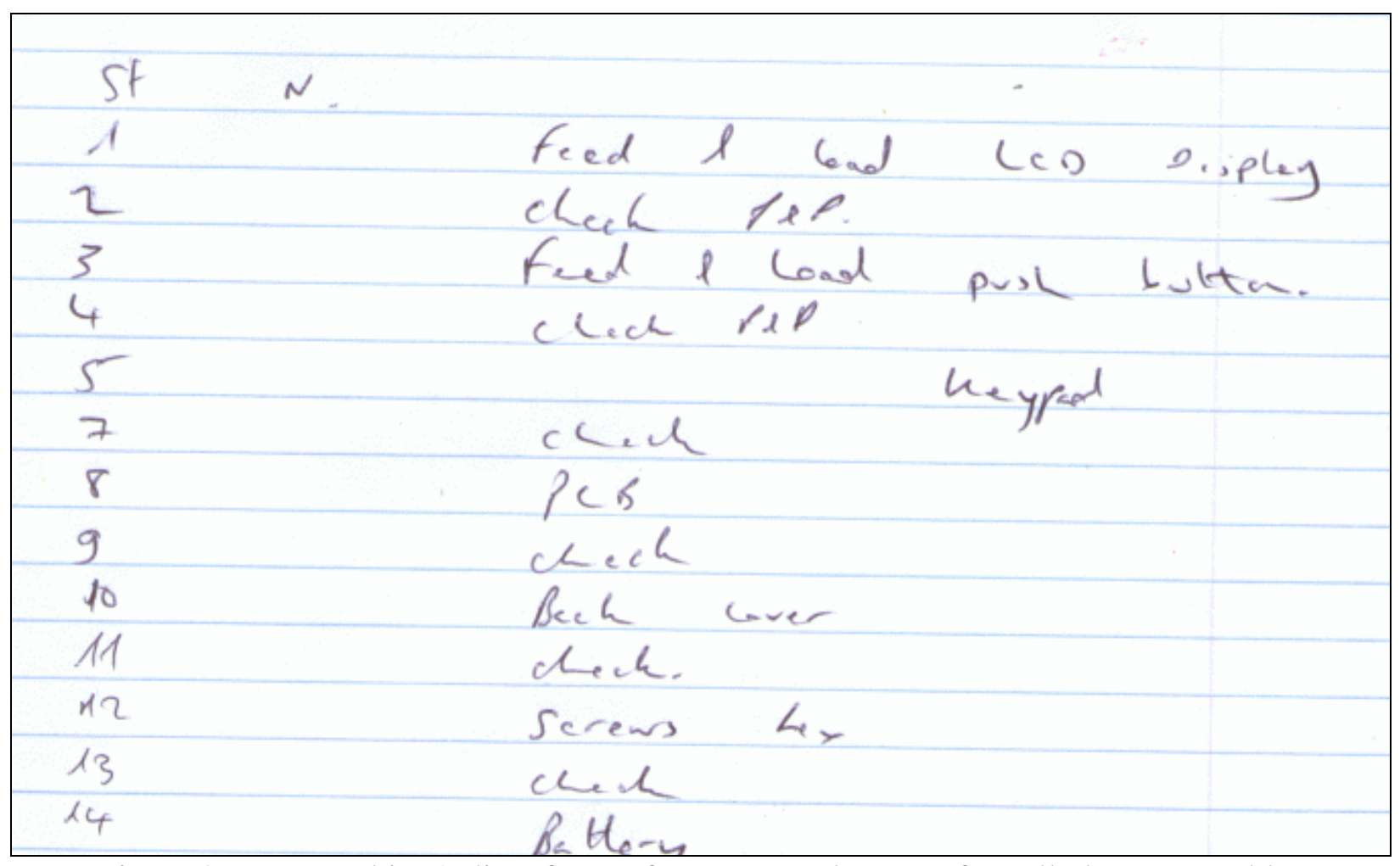

Figure 2. Expert subject's list of steps for automated system for cell phone assembly.

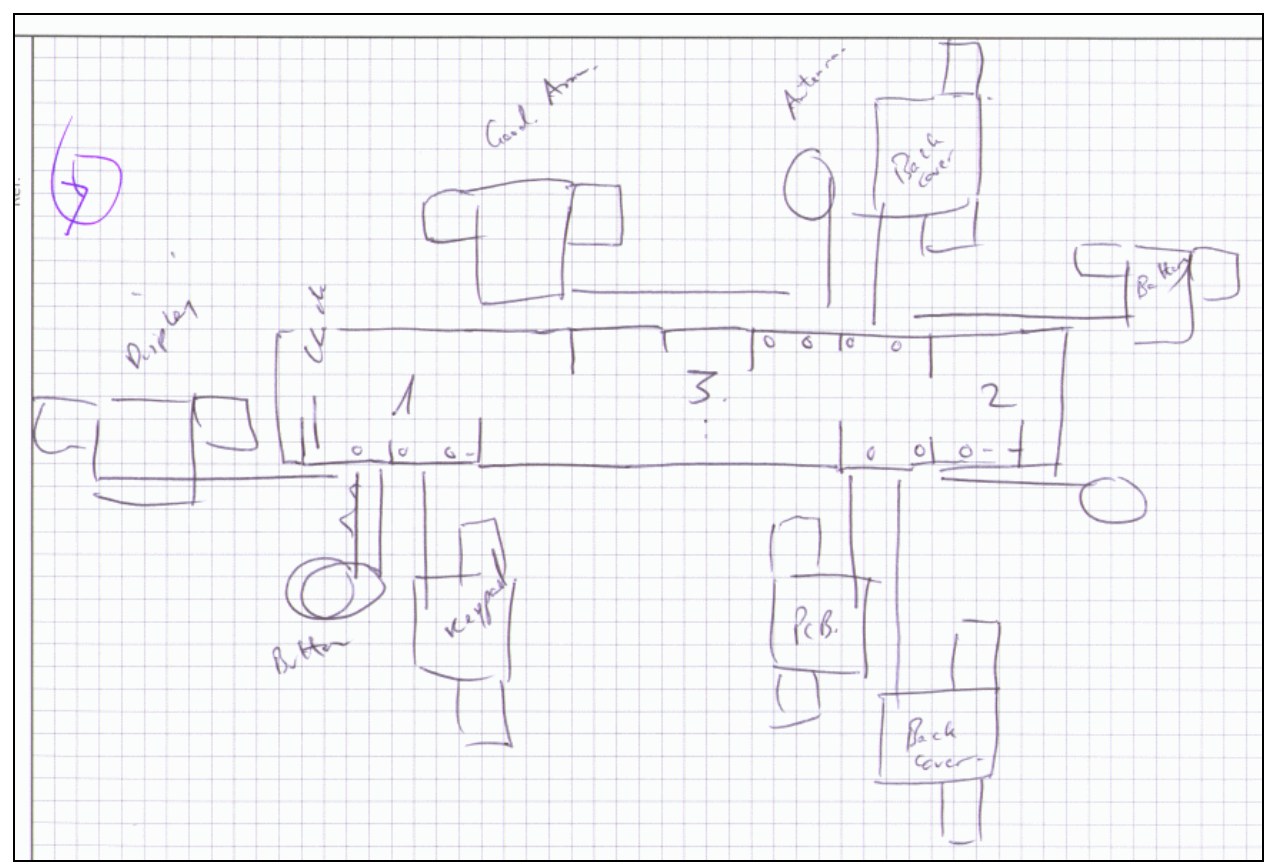

Figure 3. Expert subject's sketch of design for automated system for cell phone assembly.

The interviews were transcribed and analyzed, along with any accompanying notes (Figure 2) or drawings (Figure 3). Analyses of the following have been or are being conducted:1) educational background and work experience; 2) questions asked by engineers in the process of coming up with a design; 3) approaches to designing for specific assembly tasks, such as presenting and

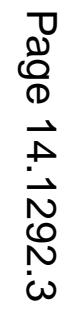


inserting various parts of a cell phone; 4) time spent on generalized engineering design steps such as problem definition, information gathering, idea generation, and modeling ${ }^{2,3}$; and 5) comparisons with data obtained from early career engineers with four or fewer years of experience. The early career engineers used automated manufacturing systems at work, but had little system design experience- that is, they were consumers, not designers of automated manufacturing system technology.

The methodology used for these interviews and some of the analysis is described in detail elsewhere ${ }^{4,5}$. This presentation will present findings related to the following research questions: 1) what types of information do applications engineers (considered to be system integration experts for the purposes of this research) attend to in coming up with a conceptual design for an automated manufacturing system, and why (in contrast to novices); 2) what do these experts know (in contrast to novices); 3) how do they approach design problems (in contrast to novices); 4) how do they compare to other experts that have been studied; and 5) what are the implications for teaching and learning about the design of automated manufacturing systems?

\section{Information that experts attend to}

The applications engineers appear to attend to more information than the novices. They are also similar to one another in that they all by and large attended to the same sorts of details for the same sorts of reasons. The novices asked relatively few questions before attempting to solve the problem and generally struggled to come up with a design. The experts seemed to know exactly what they needed to find out and look for it.

For example, in the case of the cell phone design problem, the experts looked at and touched the phone. They observed the number and size of the parts, the way they fit together, the order in which they would need to be assembled, heft, and thickness. Second, they listened closely to the given information and asked follow-up questions. Their think-aloud data indicated that they were making inferences from the given information. Third, they asked questions or made statements indicating that they were considering (or would normally consider) the following factors in making design decisions: assembly process and sequence of assembly operations; part presentation (e.g., via a tray, part feeder, or roll); desired cost, operating efficiency, and timeline; number of operators and shifts; special requirements for things such as using only certain brands of equipment, handling products a certain way (e.g., to avoid scratches), particular types of inspections or tagging; availability of documents such as part drawings and specifications; availability of sample parts; and safety and quality standards.

The experts then used this information to come up with a conceptual design or in some cases, to reframe the problem to come up with a solution that would work better for them. For example, four of the engineers worked for a company that used a proprietary cam-driven platform as a basis for all of its automated manufacturing systems. However, using this platform meant that their cell phone assembly system would probably be 3-4 times faster than the problem statement required and cost about 2-3 times as much. These engineers all noted that they would try to make a business case to the client for paying more for the system while reducing the number of shifts or operators that would be required to operate the system. As another example, one engineer noted that the cell phone power button was awkwardly positioned and could lead to a 
greater number of rejects in the assembly. He noted that he would try to persuade the client to redesign the phone so that the switch could be inserted and positioned more easily.

\section{Things the experts know about}

As expected, the experts knew much more information related to solving the problem than the novices and were able to bring it to bear as needed. In contrast, the novices seemed to struggle because they lacked the right kinds of knowledge. It was not that the novices lacked knowledge about engineering design in general (they were logical in their approach to the problem). Nor did they completely lack knowledge about automated systems; they had learned about them in school and worked with automated systems on a daily basis. However, they lacked experience with designing automated systems and the breadth of exposure to different types of systems that the experts had. The experts appeared to know about four types of things.

First, the experts knew which features of the problem to pay attention to and their implications. For example, with regard to the cell phone assembly line design problem, the fact that it was an assembly problem meant to them that the process had a certain structure-feed part, assemble part, check position and placement, repeat process with the next part. This probably helped them to remember to account for all the steps in the assembly process. None of the experts ever forgot to provide for a step. In contrast, the novices failed to account for certain assembly steps. Also, the fact that the product being assembled had an LCD display led most of the experts to note that they would need to handle the display carefully (or assemble the phone in a folded position) to avoid scratching the display. Third, the fact that the budget was $\$ 1 \mathrm{M}$ led them to assume that human operators would be involved in the assembly process. Some even went as far as to speculate that the line would likely be used in areas of the world where labor is relatively inexpensive.

Second, the experts knew about the various types of equipment available to perform assembly activities such as feeding, loading, and checking parts, and which methods and equipment would be most appropriate for given part characteristics (such as part shape or size or thickness) or assembly scenarios (such as parts that are difficult to position or fasten). Their knowledge was not necessarily very detailed (several mentioned that they would work with a vendor to figure out exactly what they needed), but they knew what options were available.

Third, the experts knew about common customer concerns and requirements, such as avoiding scratching the product or leaving enough room for operators to move around.

Finally, the experts knew about the characteristics of their own platforms or tools. To be competitive in meeting project cost and time requirements, system integrators routinely reuse as much as they can from prior projects.

\section{How experts solve design problems}

Although our novices had engineering degrees and experience in using and maintaining automated systems, and appeared to be logical problem-solvers, it was clear that they did not know where to begin when asked to design an automated system. They forgot steps. They did 
not appear to be familiar with the types of equipment available to do a task (such as part feeding) or to know what is customary. For example, one novice thought he could order screws packaged face down. In contrast, the experts did not forget steps. They knew what assembly activities needed to be accounted for and they had a large bag of tricks (methods) for getting things done.

In the case of the design problems used in this investigation (design of automated assembly lines for cell phones and truck frames), it appeared that the experts already had some idea of how to go about solving the problem from the time they first heard the problem statement. Their questions and observations were mainly intended to clarify client requirements. Unlike the novices, once the experts started thinking aloud about how they would design these systems, they described the assembly process from beginning to end and exhibited little if any hesitation. It was as if they recognized these problems and already knew how to approach them, similar to reports of expert behavior in other domains, such as physics problem solving ${ }^{6,7}$. The experts seemed to recognize these design situations as instances of more general design situations and were therefore able to quickly retrieve the knowledge needed to solve the problem.

\section{How these experts compare to other experts that have been studied}

Expertise has been studied in a variety of domains ${ }^{8,9}$, but there is relatively little reported work in the domain of automated system design expertise. It can be instructive to compare system integration expertise with expertise in other domains. So far, our findings suggest that expert system integrators are similar to experts in other domains in that they:

- Notice more things than novices. These experts attended to more aspects of the problem and asked for more information about the problem than the novices did, and more importantly, understood the implications of the information and how to apply it.

- Have a rich store of domain knowledge, such as knowledge about device characteristics, previous designs, and customer preferences.

- Have better-organized knowledge, including organized by platform (synchronous vs. asynchronous). by domain (assembly vs. process), proposal process slots, and by process or type of process.

- Do not necessarily have greater ability or greater cognitive capacity (e.g., memory) or reasoning ability. Their greater abilities appear to be context/job dependent. One could even argue that these experts are committed to some degree to avoiding originality, since presenting a competitively priced proposal often means that they need to reuse previous work as much as possible. This could cause them to be less flexible or creative than they should be in some cases.

- Exhibit automaticity in problem-solving. These experts appeared to see features or patterns in design problems that helped them to know how to begin solving them.

However, expert system integrators appear to be different from experts in other domains that have been studied in that: 
- They work collaboratively and actively leverage the knowledge of others. System integration projects typically involve teams of engineers. Several of the experts we interviewed noted that they often worked with others in their company to come up with ideas, especially for new or difficult design problems. They also call vendors for specifics about equipment.

- There is no single correct answer to a design problem. The main criterion for a satisfactory design solution is that both client and the system integrator are satisfied with the proposal. In the process of coming up with a design, the system integrator may persuade the client to accept a different kind of solution.

- The final product for application engineers-a proposal-is a good-sized product consisting of drawings, and a line-by-line, station-by-station breakdown of equipment and costs. In contrast, the outputs of expert performance in other studies of expertise tend to be relatively limited in scope-e.g., a medical diagnosis, a chess move, or a solution to a textbook physics problem.

\section{Implications for automated system design teaching and learning}

One reason it can take many years to become an expert is that the acquisition of experience is often dependent upon the types of problems that engineers encounter on the job. That is, their exposure is not systematic. Therefore, one possible way to accelerate the development of expertise is to make sure students and new engineers are systematically exposed to a representative set of manufacturing processes, automation tools and methods.

With regard to manufacturing processes, students should learn about processes that are frequently automated, such as assembly of small electronics products. In addition, students should study examples from each major class of processes-i.e., discrete (automobile manufacturing), continuous (oil refining and chemicals), and hybrid (beverage production). The instruction should make students aware of common features within each class; for example, in an assembly process, there is often a feed-load-check pattern. Learning to recognize commonalities within classes of processes will help students to understand what to do when they encounter a process that they haven't seen before.

Second, experts possess a large amount of factual knowledge about equipment and methods. Students and new engineers should be systematically taught about characteristics of assembly equipment (such as part feeders), methods of assembly, and methods of checking-including when to use each and examples. The instruction should provide many opportunities for practice in recognizing the right tool or method for a given situation.

Third, students should have the opportunity to work with and even build automated systems. However, it can be difficult for students to have access to use industry-scale automated systems. Even if a student is able to gain this type of experience by participating in a semester-long design projects or an industry internships, often their exposure is limited to a single system. Virtual design problem-solving environments can be used to help students gain experience with designing several types of systems ${ }^{10}$. 
Finally, experience alone is not sufficient to make sure the right kind of learning occurs. It is also important for learners to be debriefed after their design problem-solving experiences to make sure that the right lessons are learned.

\section{Conclusion and future directions}

Our study of expert system integrators suggests that they have well-developed knowledge about manufacturing processes, automation tools and methods, and automated systems. This helps them to know what questions to ask, what tasks to account for, and what tools and methods to use when designing an automated system. Understanding what they know about can help engineering educators to design appropriate curricula and instructional technology to accelerate the development of system integration expertise. This paper provides specific suggestions in this area.

Future directions include continued development of web-based problem-solving environments for automated system design, implementation of automated cognitive task analysis within these environments to facilitate continued research on design problem-solving, and development of an undergraduate-level system integration course.

\section{Acknowledgements}

This material was supported by a National Science Foundation grant no. 0238269. Any opinions, findings, and conclusions or recommendations expressed in this material are those of the author and do not necessarily reflect the views of the National Science Foundation.

\section{Bibliography}

1. Hsieh, S. "Automated Manufacturing System Integration Education: Current Status and Future Directions," Proceedings of 2005 ASEE Annual Conference, June 12-15, 2005, Portland, OR.

2. Atman, C.J., Adams, R.S., Cardella, M.E., Turns, J., Mosborg, S. and Saleem, J. "Engineering Design Processes: A Comparison of Students and Expert Practitioners," Journal of Engineering Education, 96(4), October, 2007, 359-379.

3. Mosborg, S., Cardella, M.E., Atman, C.J., Adams, R.S. and Turns, J. Engineering Design Expertise Study Codebook, CELT Technical Report CELT-06-02, Center for Learning and Teaching, University of Washington, Seattle, 2006.

4. Hsieh, S. "Analysis of Verbal Data from Automated System Design Problem-Solving," Proceedings of 2008 ASEE Annual Conference, June 22-25, 2008, Pittsburgh, PA.

5. Hsieh, S. "Expertise in Automated Manufacturing System Design Problem-Solving," manuscript in preparation.

6. Chi, M.T.H., Glaser, R. \& Rees, E. "Expertise in Problem Solving," Advances in the Psychology of Human Intelligence. Vol. 1, 1982, pp. 7-75.

7. Chi, M.T.H., Feltovich, P.J., and Glaser, R. "Categorization and Representation of Physics Problems by Experts and Novices," Cognitive Science, 5(2), April-June 1981, pp. 121-152.

8. Ericcson, K.A. (Ed.). The Road to Excellence: The Acquisition of Expert Performance in the Arts and Sciences, Sports, and Games, Mahwah, N.J.: Erlbaum, 1996. 
9. Ericcson, K.A. (Ed.). The Cambridge Handbook of Expertise and Expert Performance, New York: Cambridge University Press, 2006.

10. Hsieh, S. "Problem-Solving Environment for Line Balancing Automated Manufacturing Systems," Computer Applications in Engineering Education, 17(1), March 2009, pp. 52-60. 